\title{
A NOTE ON METRIC PRESERVING FUNCTIONS
}

\section{JOZEF DOBOS and ZBIGNIEW PIOTROWSKI}

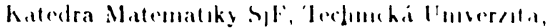

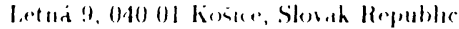 \\ anil

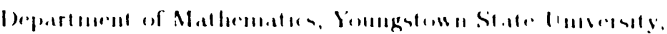

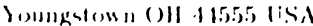

(Received March 15, 1993 and in revised form February 17, 1995)

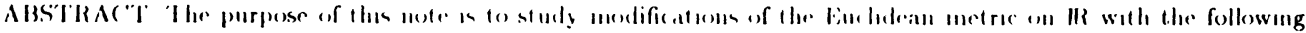

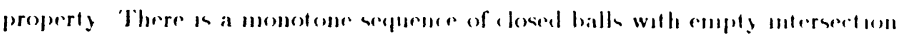

KEY WORDS ANI PIIRASES Metre preserumg functums

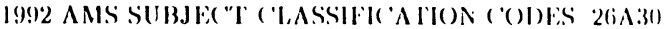

\section{IN'TROI)UE "IION}

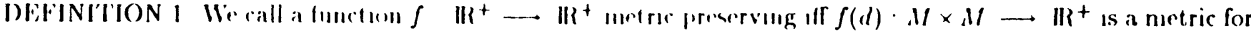

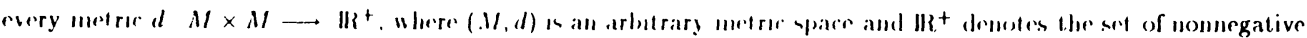

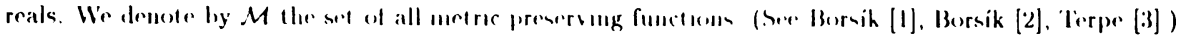

The following result is well known (sere Borsih [1], 'Terper [3])

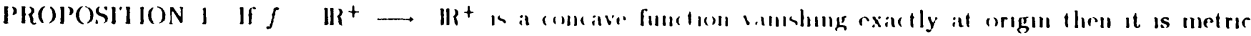
preserving

It is well known that there is a complese metre spate with the follewme preperty

There is a monotone secquence of closed balls with empty intersection.

In Juza [1] such a metric space (which is not descrete) has been combructed hy a morlification of the Euchdean metric on IIR, where II denotes the sel of reak

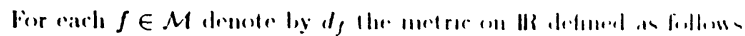

$$
d_{f}(x, y)=\int(|x-y|) \text { fior vath } x, y \text { : III }
$$

We call ds a modification of the Buchdean met rue on Ith (See Terpe [3] )

EXAMPLE, I Define $f: \mathbb{I R}^{+} \longrightarrow \mathbb{I R}^{+}$as follows

$$
f(x)=x, \text { if } x \leq 2, f(x)=1+\frac{1}{x-1} \text { if } x>2
$$

In Juza [4] it is shown that $f \in M$ and the metre space (IR, $\left.d_{f}\right)$ hi, lhe propenty (1 1$)$ The proof of (l 11$)$ is based on the following property of the metric space (IR, $\left.d_{f}\right)$.

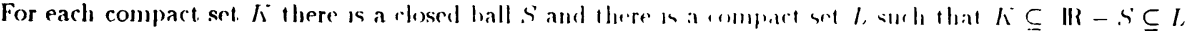


2 MAIN RLSTHISS

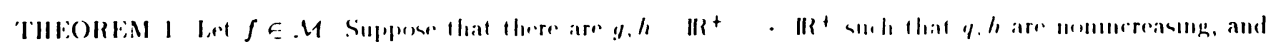

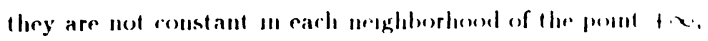

$g(x) \leq f(x) \leq h(x)$ in some neighloorhosel of the pount the.

$\operatorname{lin}_{r \rightarrow+}+\cdots g(x)=\lim _{r \rightarrow+}+\cdots h_{(x)}$

Then the metric spare (IR, df) has the prepererty (1 2)

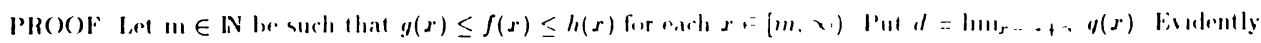

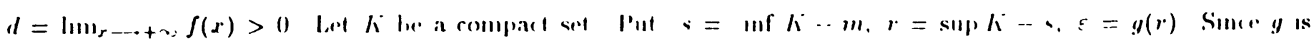

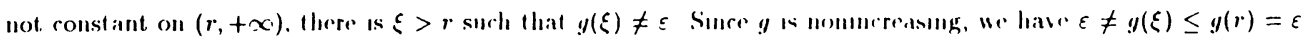

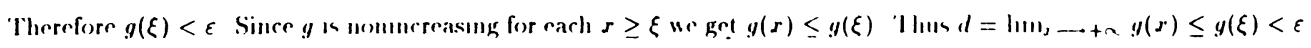
L,et. $x \in[m, r]$ Then $f(r) \geq g(x) \geq g(r)-\varepsilon$ Therefore

$$
\forall x \cdot|m, r| f(r), F
$$

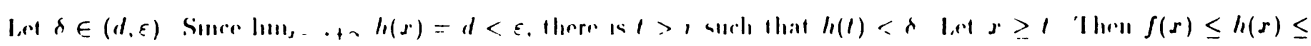
$h(1)<\gamma$ Ihus

$$
\forall x \in[t, x) \quad f(x)<\gamma
$$

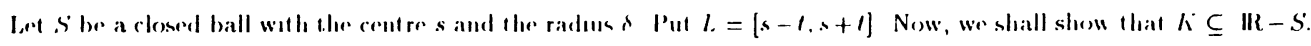
Let $u \in K$ Then $|u-s|=u-s \in[m . r]$, and by $(24)$ we get $d_{f}(u, s)=f(|u-s|) \geq \varepsilon>\delta$ Therefore $u \notin S$ Fually, we shall show that $\mathbb{R}-S \subseteq I$, Let. $n \in \mathbb{R}-. S$ Then $f(|n-s|)=d_{f}(n, s)>\delta$. By $(25)$ we have $|n-s|<t$. Therefore $v \in L$.

EXANIPLE 2 Define $f \quad \mathbb{I R}^{+} \longrightarrow \mathbb{I R}^{+}$as follows

$$
f(x)=x, 1 f x \in[0,1), f(x)=\frac{1+x+\sin ^{2}(x-1)}{2 x}, \text { if } x \in[1, \infty)
$$

It is not difficult to verify that $f \in M$ and the metrie space (IR, $d_{f}$ ) has the property (I 2 ) (which yields also the property (1.1)), however $f$ is mot monotone on every meighborheod of the point $+\infty$

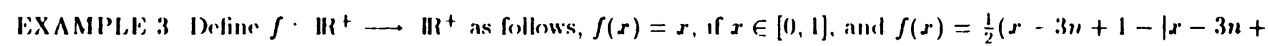
$\left.1|+| x-3 n+\frac{1}{2}+\frac{1}{n+2}|+| x-3 n-\frac{1}{2}-\frac{1}{n+2} \mid\right)$, if $x \in(3 n-2,3 n+1](n=1,2,3, \ldots)$ It is not diflicult to verify that $f \in \mathcal{M}$ and $\left(\mathbb{R}, d_{f}\right)$ is a metric space with the property (1.1), which has not. the propert.y (1.2). Indeed, the intersection of the sequence of closed balls $\left\{S_{n}\right\}_{n=1}^{\infty}$ (where $S_{n}$ has the centre $x_{n}=3\left(2^{n-1}-1\right)$ and the radius $\left.\varepsilon_{n}=\frac{1}{2}+\frac{1}{2^{n}+1}\right)$ is cmpty.

$\Lambda$ characterization of unetric preserving functions $f$ such that the space (IR, $d_{f}$ ) has the property (1.1) remains an open question.

A(:KNOWLED(iEMEN'T: The first named author wishes to express hiss apprectation to the Department of Mathematics, Youngstown State University for their hospitality during his stay 'The second uamed author wishes to acknowledge a support from Youngstown State University Research (:ouncil

\section{REFERENCES}

1. BORSIK, J. and DOBOŚ, J Functions whose composition with every metric is a met rıe, Math. Slovaca 31(1981), 3-12 (in Russian).

2. BORSÍK, J. and DOBOŠ, J On metric preserving functions, Real Analysis Exchange 13 (1987-88), 285-293

3. TERPE, F. Metric preservice fucntiosn, Proc Conf. Topology and Measure IV, (ireifswald, 1984, 189-197.

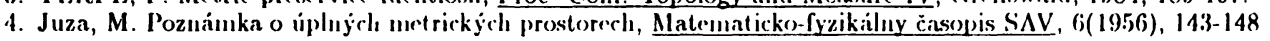




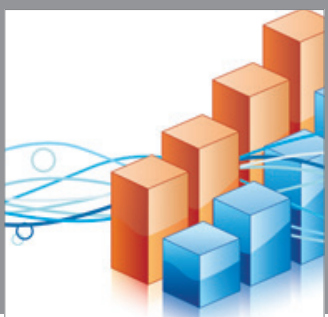

Advances in

Operations Research

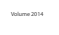

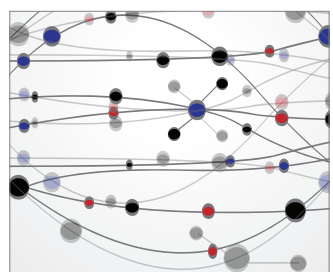

\section{The Scientific} World Journal
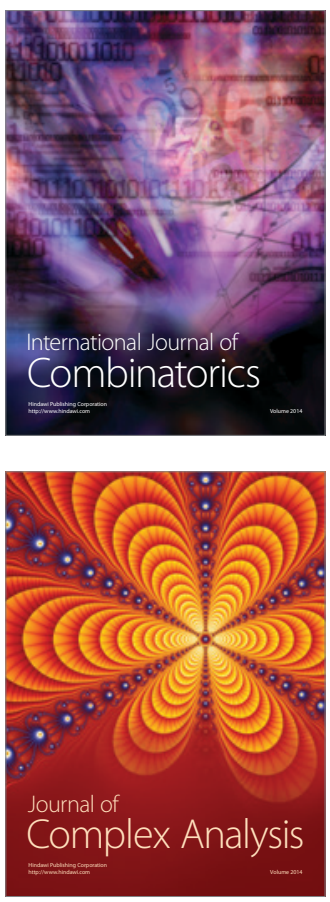

International Journal of

Mathematics and

Mathematical

Sciences
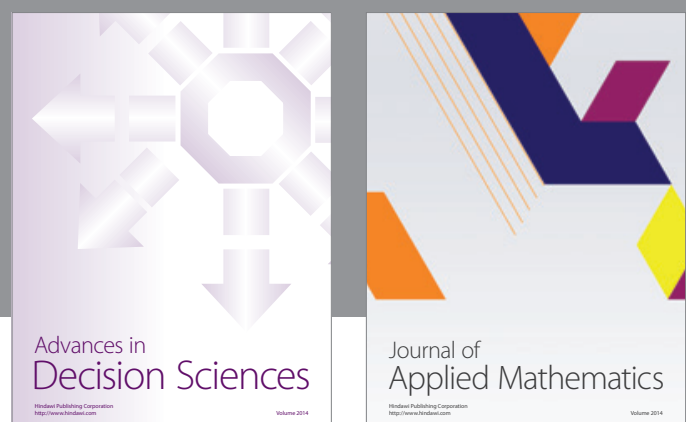

Journal of

Applied Mathematics
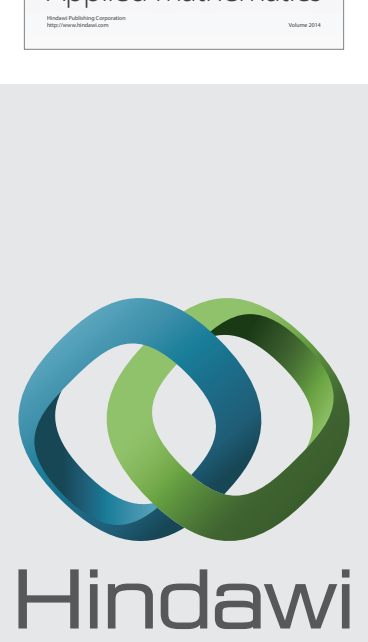

Submit your manuscripts at http://www.hindawi.com
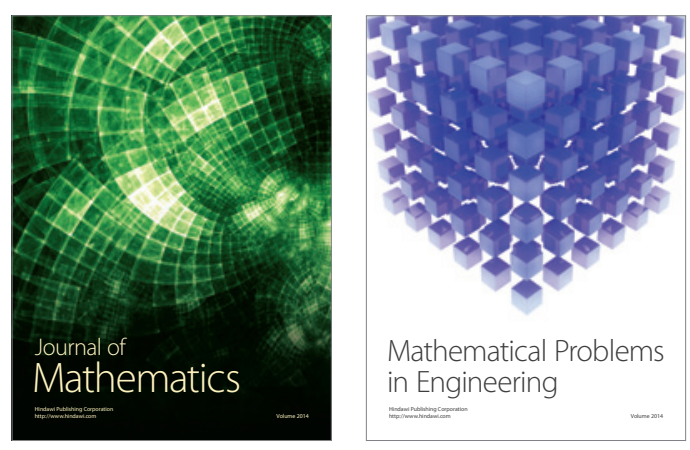

Mathematical Problems in Engineering
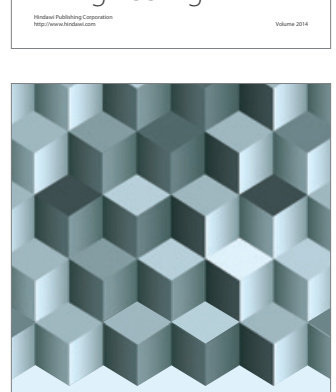

Journal of

Function Spaces
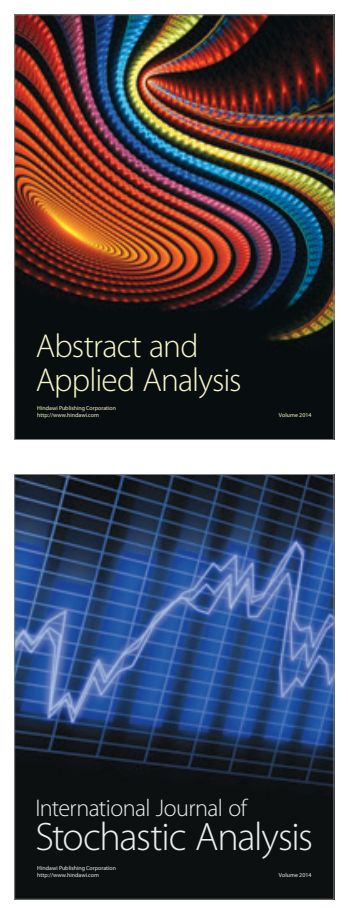

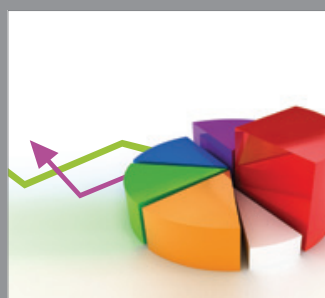

ournal of

Probability and Statistics

Promensencen
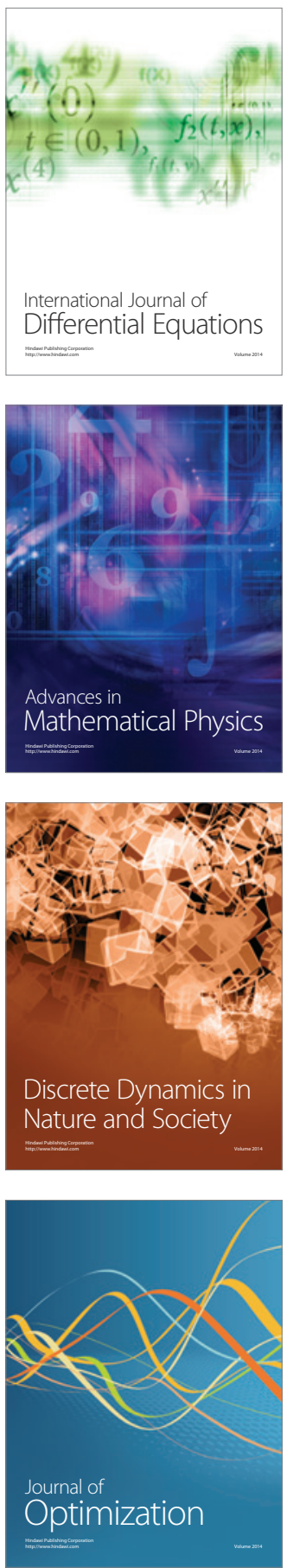